\title{
Blood Coagulation and Asthma Exacerbation in Children
}

\author{
Wiparat Manuyakorn Dara Mairiang Nongnuch Sirachainan \\ Praguywan Kadegasem Wasu Kamchaisatian Suwat Benjaponpitak \\ Ampaiwan Chuansumrit
}

Department of Pediatrics, Faculty of Medicine, Ramathibodi Hospital, Mahidol University, Bangkok, Thailand

\section{Key Words}

Asthma exacerbation - Children · von Willebrand factor .

Plasminogen activator inhibitor type- 1 . Protein C

\begin{abstract}
Background: Recent studies have demonstrated the activation of coagulation pathways in asthmatic airways. This study aimed to determine systemic blood coagulation during asthma exacerbation compared with the stable state in children. Methods: Pediatric patients (aged between 5 and 15 years) suffering from asthma exacerbation were enrolled. von Willebrand factor (VWF), plasminogen activator inhibitor type-1 (PAI-1), protein C, D-dimer, prothrombin fragment $1+2(\mathrm{~F} 1+2)$, thrombin-antithrombin complex (TAT), and Creactive protein (CRP) levels were measured during asthma exacerbation and stable state. Results: A total of 22 patients were enrolled. The median VWF, PAI-1, and CRP during asthma exacerbation were significantly higher than those of the stable state: $147.5 \%$ (interquartile range, IQR: 111.05-196.57) versus 94\% (IQR: 69.72-109.62, $\mathrm{p}<0.001), 41.9 \mathrm{ng} / \mathrm{ml}$ (IQR: 21.91-48.61) versus $26.17 \mathrm{ng} / \mathrm{ml}$ (IQR: 15.89-34.44, $\mathrm{p}<0.03)$, and $4.46 \mathrm{mg} / \mathrm{l}$ (IQR: $2.15-16.23$ ) versus $0.87 \mathrm{mg} / \mathrm{l}$ (IQR: 0.20 $3.89, p<0.015)$, respectively. However, the median protein $C$ during asthma exacerbation was significantly lower than that of the stable state: $99.5 \%$ (IQR: $86.75-117$ ) versus $113 \%$
\end{abstract}

\section{KARGER}

E-Mail karger@karger.com

www.karger.com/iaa
(IQR: 94-115.25), $\mathrm{p}=0.01$. No significant difference was found between the levels of D-dimer, F1 +2 , and TAT during asthma exacerbation and stable state. Ultimately, D-dimer was positively correlated with asthma exacerbation score $(R=0.466, p=0.027)$. A significant correlation was observed between vWF and CRP $(R=0.527, p=0.012)$. Conclusion: Evidence was found of increased endothelial activation and increased PAI-1 during asthma exacerbation. This may emphasize the potential role of blood coagulation in asthma exacerbation.

(c) 2016 S. Karger AG, Basel

\section{Introduction}

Asthma is a chronic eosinophilic and T-helper type 2 (Th2) airway inflammation leading to variable airway obstruction [1]. Recently, increasing evidence has been found of coagulation activation in the airways of asthmatic subjects after allergen challenges [2-4]. In addition to the local airway inflammation, systemic inflammation demonstrated by increased C-reactive protein (CRP) levels has been reported among asthmatic subjects compared with healthy controls [5]. The level of CRP has been shown to be higher during asthma exacerbation or exercise-induced bronchoconstriction in asthmatic patients (c) 2016 S. Karger AG, Basel

$1018-2438 / 16 / 1702-0075 \$ 39.50 / 0$
Correspondence to: Prof. Ampaiwan Chuansumrit

Division of Hematology-Oncology, Department of Pediatrics

Faculty of Medicine, Ramathibodi Hospital, Mahidol University

Rama VI Road, Bangkok 10400 (Thailand)

E-Mail ampaiwan.jua@ mahidol.ac.th 
Table 1. Clinical asthma exacerbation score

\begin{tabular}{|c|c|c|c|c|}
\hline & 0 & 1 & 2 & 3 \\
\hline Respiratory rate/min & $<30$ & $31-40$ & $41-50$ & $>50$ \\
\hline Wheezing & none & expiratory & inspiratory and expiratory & poor air entry \\
\hline Pulse oxygen saturation & $>95 \%$ on room air & $90-94 \%$ on room air & $<90 \%$ on room air & $<90 \%$ with oxygen supplement \\
\hline
\end{tabular}

Retraction: suprasternal, intercostal, and subcostal retraction.

[5-8]. The link between inflammation and coagulation has been well demonstrated in systemic inflammatory diseases such as sepsis [9], dengue virus infections [10], and acute respiratory tract infections [11]. We hypothesized that during asthma exacerbation, airway and systemic inflammations increased, resulting in the activation of the systemic coagulation pathway. The coagulation system consists of three main parts, namely, clot formation from the activation of coagulation factors (including factors V, VII, VIII, IX, and X), anticoagulants to prevent clot formation, and fibrinolysis to lyse the existing clots. The objective of this study was to compare the levels of endothelial activation, coagulation marker, anticoagulant, and fibrinolysis during asthma exacerbation and the stable state. Therefore, von Willebrand factor (vWF) was measured to find evidence of endothelial activation. Plasminogen activator inhibitor type-1 (PAI-1) was used as an indicator of fibrinolytic function. Protein $\mathrm{C}$ was measured to determine anticoagulant activity. Coagulation markers, including D-dimer, prothrombin fragment $1+2(\mathrm{~F} 1+2)$, and thrombin-antithrombin complex (TAT), were measured. D-dimer, the smallest subunit of fibrin degradation products, was used as a marker of coagulation and fibrinolysis. F1 +2 and TAT were evaluated as markers of clot formation.

\section{Patients and Methods}

\section{Patients}

Pediatric patients (aged between 5 and 15 years) at Ramathibodi Hospital, Bangkok, Thailand, suffering from asthma exacerbation between May 2013 and March 2014 were enrolled in the study. Patients with a personal history of coagulation disorders or thrombosis, cardiovascular diseases or airway anomalies, systemic inflammatory diseases, severe infection, major trauma, receiving blood transfusions within the previous 3 months, or receiving medications disturbing coagulation (such as systemic corticosteroids) were excluded.

\section{Study Design and Protocol}

This study was a prospective observational design. After patient enrollment, the severity of asthma exacerbation was assessed using an asthma exacerbation score (table 1) [12]. A total score between 1 and 4 was considered as mild asthma exacerbation, 5-8 as moderate asthma exacerbation, and $>8$ as severe asthma exacerbation. Baseline characteristics including age, sex, severity of asthma, control of asthma as assessed by the Global Initiative for Asthma Guidelines [13], and absolute eosinophil count in the peripheral blood were recorded. Two blood samples were collected to measure blood coagulation. The first sample was collected during the period of asthma exacerbation before systemic corticosteroid administration. The time period from symptom onset of asthma exacerbation to the first blood sampling was defined as the duration of asthma exacerbation in the current study. The second blood sample was collected in the morning during the stable state, defined by the Global Initiative for Asthma Guidelines as controlled or partly controlled asthma for at least 3 months after asthma exacerbation. The blood samples were collected in sodium citrate coagulation tubes and centrifuged to separate plasma. The plasma was immediately aliquoted and frozen at $-80^{\circ} \mathrm{C}$ in a laboratory freezer. The sample aliquots were thawed and analyzed once without a repeated freeze-thaw cycle. This study was reviewed and approved by the Research Ethics Committee of the Faculty of Medicine, Ramathibodi Hospital, Mahidol University, Bangkok, Thailand. Written informed consent was obtained from the parents of the patients.

Measurement of $v W F, P A I-1$, Protein C, Coagulation Markers, and CRP

vWF antigen was measured using a previously reported enzyme-linked immunosorbent assay [14]. Standard known vWF plasma of $99 \%$ was purchased from Siemens Health Care Diagnostics Products, GmbH, Germany for the calibration curve. Protein $\mathrm{C}$ activity was measured using an automated functional clotting protein $\mathrm{C}$ assay (Instrumentation Laboratory, Bedford, Mass., USA) based on the prolongation of activated partial thromboplastin time in the presence of activated protein C on the ACL 200 automated coagulation analyzer (Beckman Coulter, Fullerton, Calif., USA). Standard known activated protein C plasma of $100 \%$ from the manufacturer was used for the calibration curve. PAI-1 was measured using an enzyme-linked immunosorbent assay (Sekisui, Stamford, Conn., USA). D-dimer was assayed using an enzymelinked fluorescence assay (Biomérieux, Marcy l'Étoile, France).
Manuyakorn et al. 
F1 +2 and TAT were analyzed using a sandwich enzyme immunoassay (Siemens, Marburg, Germany). CRP was analyzed using an enhanced immunoturbidimetric assay (Abbott Laboratories, Abbott Park, Ill., USA). All measurements were performed according to the manufacturer's instructions.

\section{Statistical Analysis}

Statistical analysis was performed using SigmaPlot software version 12. Descriptive statistical methods (mean $\pm \mathrm{SD}$, median with interquartile range, IQR, and frequency) were used. Analyses of the differences in CRP and blood coagulation levels during asthma exacerbation and the stable state were performed using the Wilcoxon signed-rank test. The differences in blood coagulation levels among the three groups of the duration of asthma exacerbation were analyzed using the Kruskal-Wallis test. Linear regression analysis was used to correlate blood coagulation levels and the asthma exacerbation score. Correlation between blood coagulation levels and CRP was analyzed using liner regression analysis. A $p$ value of $<0.05$ was considered statistically significant.

\section{Results}

Twenty-two patients were enrolled, $54 \%$ of whom were male. Their mean age $( \pm \mathrm{SD})$ was $8.5 \pm 3.0$ years. The median clinical asthma exacerbation score was 4 (IQR: $2-5)$. Sixteen patients $(73 \%)$ had mild asthma exacerbation, while 6 patients (27\%) had moderate asthma exacerbation. No patient with severe asthma exacerbation was enrolled. The median duration of asthma exacerbation was $12 \mathrm{~h}$ (IQR: 4.88-15.50). The major precipitating causes were upper respiratory tract infection (67\%) and poor compliance or improper drug administration (33\%). The median absolute eosinophil count in the peripheral blood was 244 cells/ $\mu$ (IQR: 142.5-467.5), and median CRP during asthma exacerbation was $4.46 \mathrm{mg} / \mathrm{l}$ (IQR: 2.16-15.45). Baseline characteristics of the patients before enrollment are presented in table 2 .

\section{Comparison of CRP, vWF, PAI-1, Protein C, and Coagulation Markers during Asthma Exacerbation and the Stable State}

The median CRP during asthma exacerbation was significantly higher than that of the stable state: $4.46 \mathrm{mg} / \mathrm{l}$ (IQR: 2.15-16.23) versus $0.87 \mathrm{mg} / \mathrm{l}$ (IQR: 0.20-3.89), $\mathrm{p}<$ 0.015 . The median vWF during asthma exacerbation was significantly higher than that of the stable state: $147.5 \%$ (IQR: 111.05-196.57) versus 94\% (IQR: 69.72-109.62), $\mathrm{p}<0.001$ (fig. 1a). The median PAI-1 during asthma exacerbation was significantly higher than that of the stable state: $41.9 \mathrm{ng} / \mathrm{ml}$ (IQR: 21.91-48.61) versus $26.17 \mathrm{ng} / \mathrm{ml}$ (IQR: 15.89-34.44), $\mathrm{p}<0.03$ (fig. 1b). The median protein $\mathrm{C}$ during asthma exacerbation was significantly lower
Table 2. Baseline characteristics of enrolled subjects

\begin{tabular}{lc}
\hline & $\begin{array}{c}\text { Asthmatic } \\
\text { children }(\mathrm{n}=22)\end{array}$ \\
\hline Age, years & $8.6(6-11)$ \\
Female:male & $9: 13$ \\
Asthma severity & \\
$\quad$ Mild & $10(45.5)$ \\
$\quad$ Moderate & $7(31.8)$ \\
Severe & $5(22.7)$ \\
Inhaled corticosteroid0a ${ }^{, \mu g}$ & \\
$\quad 0$ & $11(50)$ \\
$\quad 400$ & $4(18.2)$ \\
$\quad 800$ & $7(31.8)$ \\
Level of asthma control before exacerbation & \\
$\quad$ Well controlled & $15(68.2)$ \\
Party controlled & $3(13.6)$ \\
$\quad$ Uncontrolled & $4(18.2)$ \\
Severity of asthma exacerbation & \\
$\quad$ Mild & $16(72.7)$ \\
Moderate to severe & $6(27.3)$ \\
Blood eosinophil count, cells/ $\mu \mathrm{l}$ & $244(142.5-476.5)$
\end{tabular}

Values are presented as median (IQR) or n (\%), unless otherwise

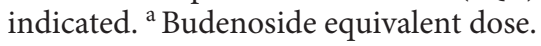

than that of the stable state: 101\% (IQR: 87.5-117) versus 112\% (IQR: 92.65-154.5), $\mathrm{p}=0.01$ (fig. 1c). Median levels of D-dimer, F1 + 2, or TAT did not significantly differ between the asthma exacerbation and the stable state (fig. 1d-f).

Correlation between CRP, vWF, PAI-1, Protein C, and Coagulation Markers and Severity of Asthma Exacerbation

A significant correlation was observed between D-dimer and asthma exacerbation score: $\mathrm{R}=0.466, \mathrm{p}=0.027$ (fig. 2d). However, no significant correlations were demonstrated between other parameters, including vWF, PAI-1, protein C, F1 + 2, and TAT, and asthma exacerbation score (fig. 2). No significant correlation was observed between CRP and asthma exacerbation score: $\mathrm{R}=0.294$, $\mathrm{p}=0.185$.

\section{Correlation between $v W F$, PAI-1, Protein C, and Coagulation Markers and Duration of Asthma Exacerbation}

The kinetic changes of blood coagulation during asthma exacerbation with different durations of asthma exacerbation were further analyzed. Patients experiencing 


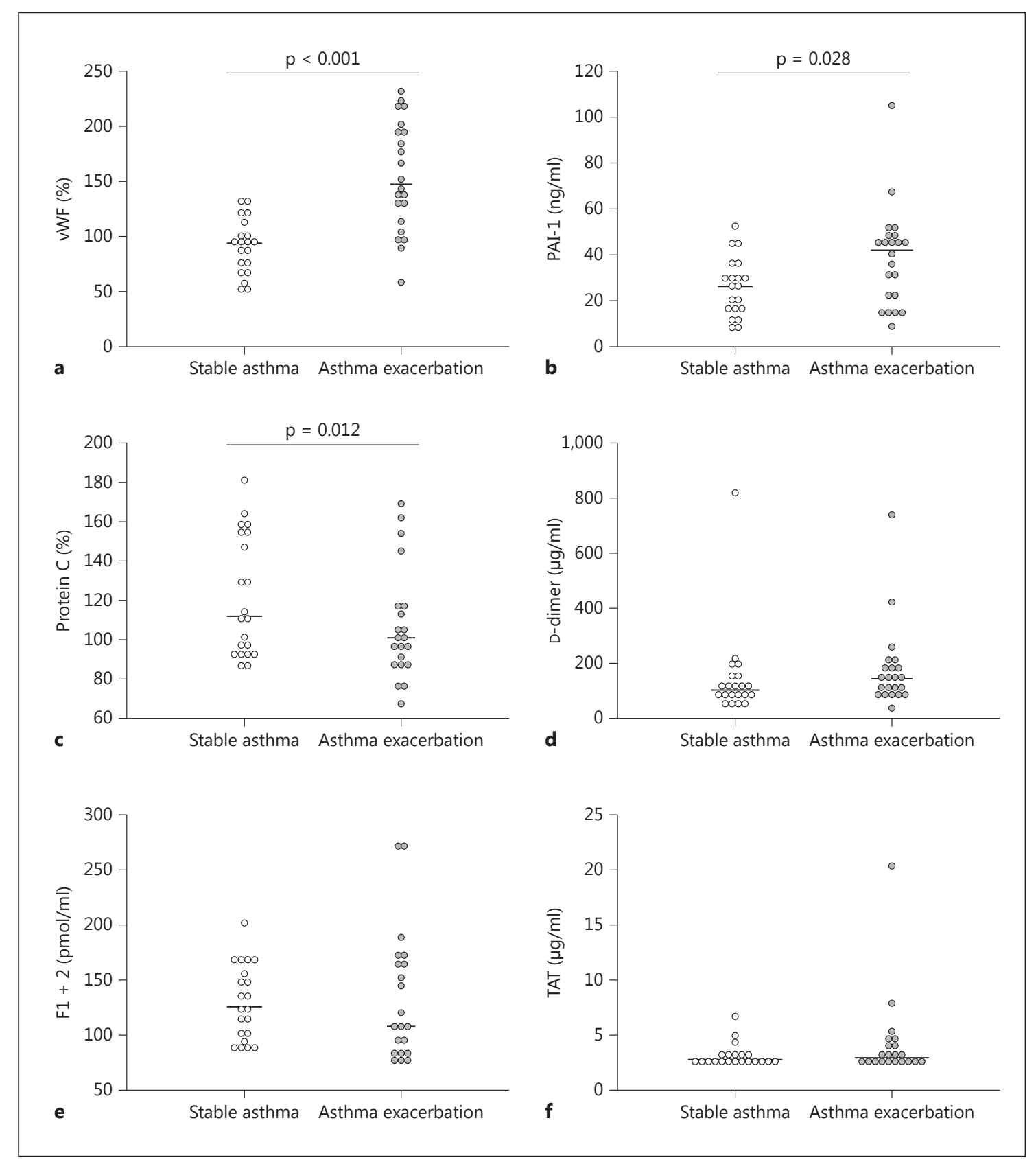

Fig. 1. Comparison of vWF (a), PAI-1 (b), protein C (c), D-dimer (d), F1 + 2 (e), and TAT (f) during asthma exacerbation and stable state.

asthma exacerbation for $<7 \mathrm{~h}$ had significantly lower levels of protein $\mathrm{C}$ than those experiencing asthma exacerbation for $7-12 \mathrm{~h}$ or $>12 \mathrm{~h}(\mathrm{p}<0.05$; fig. 3c). In contrast, levels of vWF, PAI-1, D-dimer, F1 + 2, and TAT did not significantly differ among patients with different durations of asthma exacerbation (fig. 3).
Correlation between vWF, PAI-1, Protein C, and Coagulation Markers and CRP Level Exacerbation

A significant correlation was observed between vWF and CRP: $\mathrm{R}=0.527, \mathrm{p}=0.012$ (fig. 4a). However, no significant correlations were demonstrated between other parameters, including PAI-1, protein C, D-dimer, F1 + 2, and TAT, and CRP (fig. 4). 


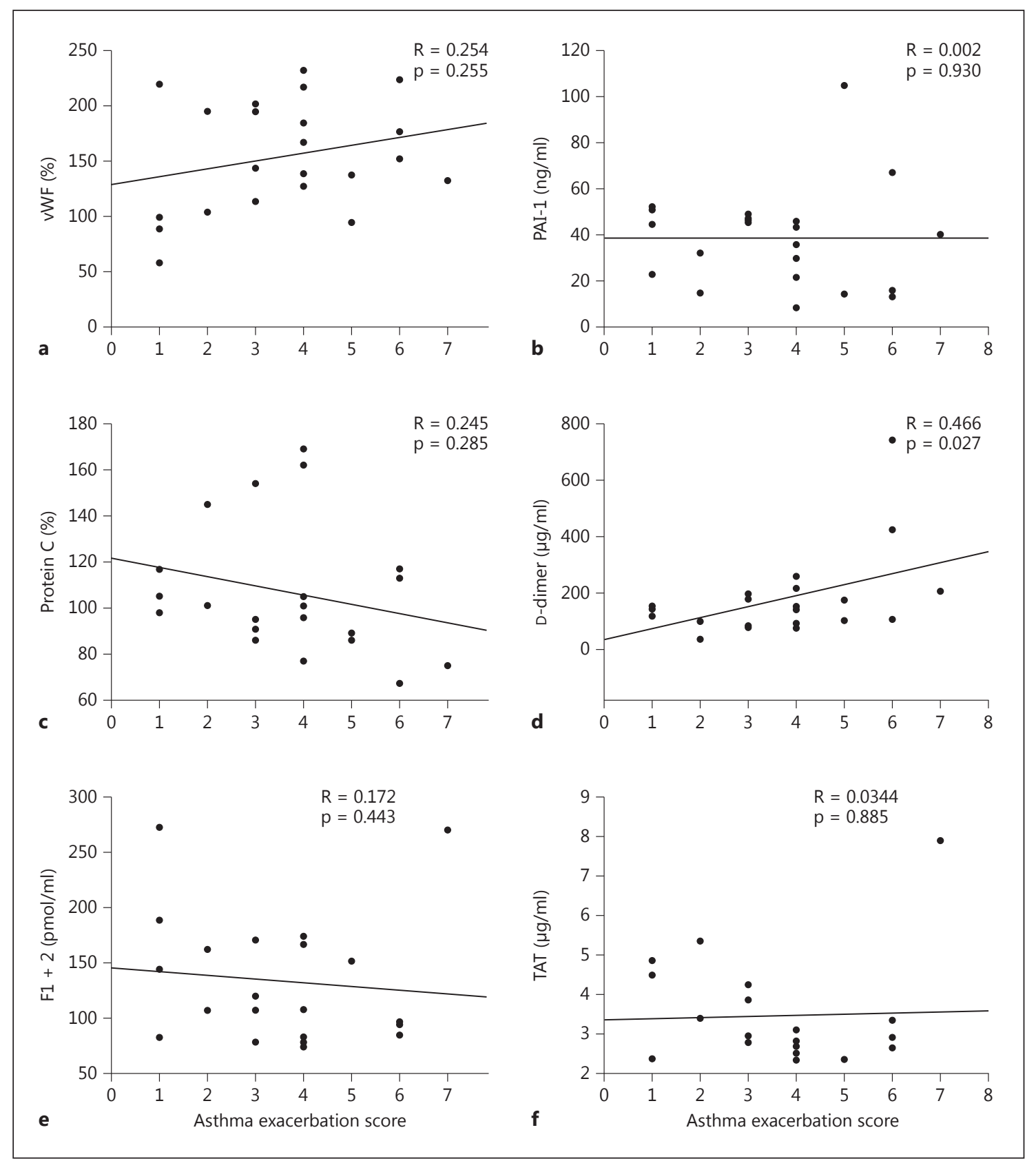

Fig. 2. Correlation of vWF (a), PAI-1 (b), protein C (c), D-dimer (d), F1 + $2(\mathbf{e})$, and TAT (f) with asthma exacerbation score.

Comparison of CRP, vWF, PAI-1, Protein C, and Coagulation Markers between Causes of Asthma Exacerbation

The median level of CRP from children who had asthma exacerbation from respiratory tract infection was not significantly different from those with asthma exacerbation from poor drug compliance or improper drug ad- ministration: $4.34 \mathrm{mg} / \mathrm{l}$ (IQR: 2.13-13.83) versus 4.58 $\mathrm{mg} / \mathrm{l}$ (IQR: 1.92-27.70), $\mathrm{p}=0.8$. No significant differences in the levels of vWF, PAI-1, protein C, D-dimer, and TAT were observed between children who had asthma exacerbation from respiratory tract infections and those from poor drug compliance or improper drug administration - vWF: $138.2 \%$ (IQR: 101.4-189.35) versus 194.9\% 


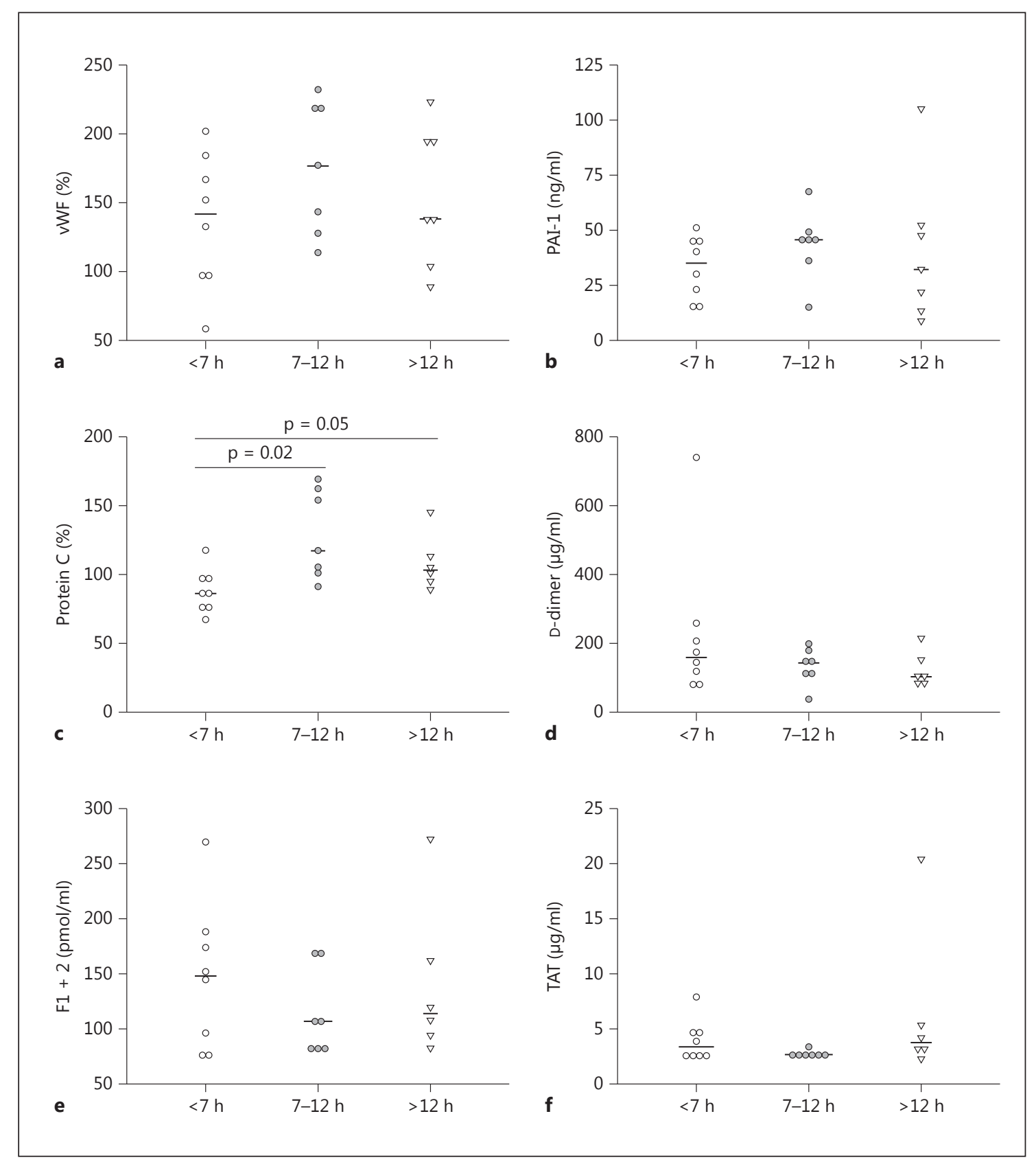

Fig. 3. Comparison of $\operatorname{vWF}(\mathbf{a})$, PAI-1 (b), protein C (c), D-dimer (d), F1 + 2 (e), and TAT (f) with duration of asthma exacerbation.

(IQR: 154.55-224.5), $\mathrm{p}=0.08$; PAI-1: $43.62 \mathrm{ng} / \mathrm{ml}(\mathrm{IQR}:$ 22.24-48.23) versus $40.18 \mathrm{ng} / \mathrm{ml}$ (IQR: $11.59-56.52), \mathrm{p}=$ 0.6; protein C: $97 \%$ (IQR: $86.75-116$ ) versus $101 \%$ (IQR: 88-143), $\mathrm{p}=0.53$; D-dimer: $143 \mu \mathrm{g} / \mathrm{ml}$ (IQR: 95-187) versus $141 \mu \mathrm{g} / \mathrm{ml}$ (IQR: 70.5-210), $\mathrm{p}=1$; F1 + 2: $113.1 \mathrm{pmol} /$ $\mathrm{ml}$ (IQR: $82.31-168.16), \mathrm{p}=0.6$, and TAT: $2.93 \mu \mathrm{g} / \mathrm{ml}$ (IQR: 2.34-4.42), $\mathrm{p}=0.7$.

\section{Discussion}

Previously, coagulation and fibrinolysis have been regarded as processes that occurred only in blood vessels. Coagulation and anticoagulation are known to be activated locally in the airways, particularly in the inflamed airways, by conditions such as acute respiratory distress 


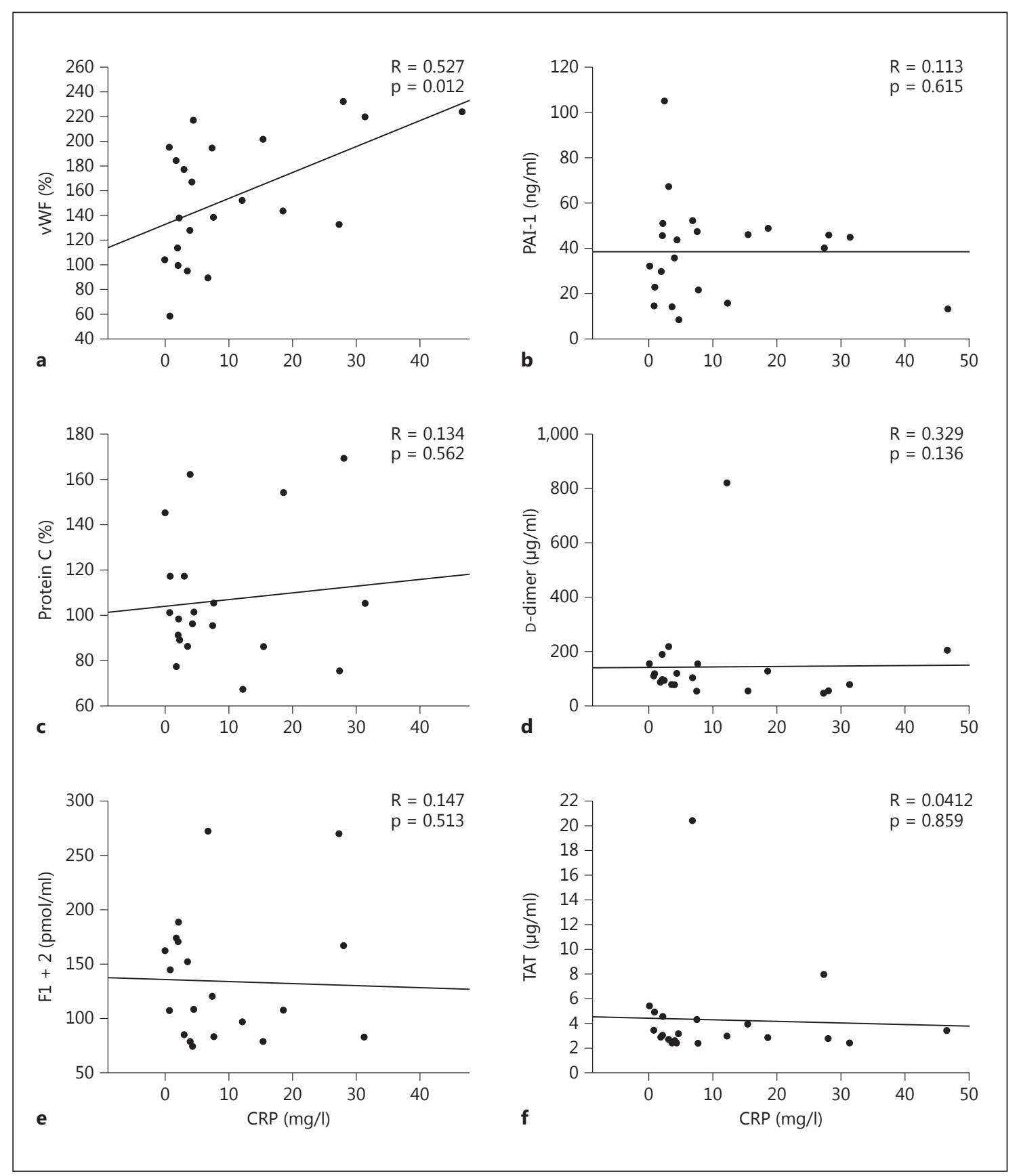

Fig. 4. Correlation of $\mathrm{vWF}(\mathbf{a}), \operatorname{PAI}-1$ (b), protein C (c), D-dimer (d), F1 + 2 (e), and TAT (f) with CRP.

syndrome, pneumonia, lung fibrosis, and respiratory viral infections [15]. Patients with influenza-like respiratory tract infections had significant changes in blood coagulation levels compared with their baseline levels [11].

The coagulation system consists of three main pathways: clot formation, fibrinolysis, and anticoagulation. In this study, we compared the levels of vWF, PAI-1, protein
$\mathrm{C}$, and coagulation markers during asthma exacerbation and the stable state among pediatric patients. We have demonstrated that the median levels of vWF and PAI-1 during asthma exacerbation were significantly higher than those of the stable state. Both vWF and PAI-1 are stored in the endothelial cells [16]. During the stable state, the inactivated endothelial cells were driven by the hemo- 
static balance in favor of fibrinolysis through activated protein $\mathrm{C}$ generation and the production of tissue plasminogen activator $[16,17]$. Activated protein $C$ has been shown to neutralize PAI-1, which indirectly leads to an increase in fibrinolytic activity [18]. Increased vWF and PAI-1 during asthma exacerbation can be explained by the activation of the endothelium, whereby both vWF and PAI-1 are released. Majoor et al. [19] evaluated the plasma vWF, PAI-1, and coagulation markers after rhinovirus infection, a common cause of asthmatic exacerbation, in mild asthma patients and healthy controls. The rhinovirus infection led to significantly higher plasma PAI-1 levels in asthmatic patients than those in controls. Notably, the increased PAI-1 levels after rhinovirus infection were also significantly higher than the patients' baseline levels [19]. In the current study, we have demonstrated increased PAI-1 and decreased activated protein $\mathrm{C}$ in the patients' plasma during asthma exacerbation. An increased PAI-1 level impairs fibrinolysis, and then the promotion of clot formation will occur. Simultaneously, the activated protein $\mathrm{C}$ possesses an anticoagulant activity as well as enhancing fibrinolysis, leading to the balance of the coagulation system. In addition, we have demonstrated the positive correlation of D-dimer, the smallest subunit of fibrin degradation products from clot formation and fibrinolysis, and the severity of asthma exacerbation represented by the clinical asthma exacerbation score. A decreased level of protein $\mathrm{C}$ during asthma exacerbation was also demonstrated in the current study. Ultimately, an increased amount of clot formation and impaired fibrinolysis would occur in patients exhibiting severe asthma exacerbation resulting from increased PAI- 1 and decreased protein C. Anticoagulants such as heparin or activated protein $\mathrm{C}$ may have a role during severe asthma exacerbation. Intravenous heparin has been shown to improve asthma symptoms in previous studies [20, 21]. However, the current study could not demonstrate increased clot formation during asthma exacerbation expressed as F1 +2 and TAT. This is possibly explained by the fact that the asthma exacerbation in this study was not severe enough, so the fibrinolytic and anticoagulant processes could be kept in balance.

In a subgroup analysis on the causes of asthma exacerbation, we did not find significant differences in the levels of CRP, vWF, PAI-1, protein C, and coagulation markers between children who had asthma exacerbation from respiratory tract infection and those from poor compliance. As a result, the changes in vWF, PAI-1, and protein C during asthma exacerbation should be explained from asthma but not from respiratory tract infection.
The activation of protein $\mathrm{C}$ during asthma exacerbation has been demonstrated in the airways $[2,22]$. We have shown decreased protein $\mathrm{C}$ in the blood during asthma exacerbation compared with the stable state. As a result, the activation of protein $\mathrm{C}$ (to become activated protein C) could also happen systematically during asthma exacerbation. Also, the levels of protein $\mathrm{C}$ among patients with different asthma exacerbation durations differed significantly. It was found that those with asthma exacerbation for $<7 \mathrm{~h}$ had the lowest protein $\mathrm{C}$ levels. It has been postulated that the coagulation pathway was activated during early asthma exacerbation, and protein $\mathrm{C}$ was used. After $7 \mathrm{~h}$ of asthma exacerbation, the coagulation system could maintain the equilibrium through the increased production of protein $\mathrm{C}$.

Inflammation and coagulation are closely linked. When inflammation occurs, activation of the coagulation pathway actively supports increasing inflammation [23]. Similar to related studies [5-8], we have also demonstrated increased CRP during asthma exacerbation compared with the stable stage. However, no significant association was observed between asthma exacerbation severity and levels of PAI-1, protein C, coagulation markers, and CRP. We have observed a significant association between CRP and vWF during asthma exacerbation. This finding can be explained from the link between systemic inflammation and endothelial activation.

Although asthma exacerbation is considered to be an inflammatory process of airways locally, our study demonstrated that coagulation in the blood stream is also affected. Changes in vWF, PAI-1, and protein C level were observed during asthma exacerbation. The strength of our study was the actual situation of asthma exacerbation compared with the stable state individually. In addition, blood samples were drawn before corticosteroid administration, possibly affecting the inflammation and coagulation outcomes. Because all studied patients were categorized as having mild or moderate asthma severity by the clinical asthma score, the changes in inflammation and coagulation were minimal. Therefore, all patients were responsive to counterbalance, leading to the normal values of the majority of the laboratory tests compared with the normal value from our laboratory: $\mathrm{vWF}=50-150 \%$, PAI- $1=4-43 \mathrm{ng} / \mathrm{ml}$, protein C $=64-$ $141 \%$, D-dimer $<500 \mathrm{ng} / \mathrm{ml}, \mathrm{F} 1+2=69-229 \mathrm{pmol} / \mathrm{ml}$, and TAT $=2-4.2 \mu \mathrm{g} / \mathrm{ml}$. When inflammation is severe, the activation of the coagulation cascade will be prominent, resulting in a more severe coagulation derangement or disseminated intravascular coagulation. The levels of vWF, PAI-1, protein C, and coagulation markDOI: $10.1159 / 000446775$
Manuyakorn et al. 
ers should be abnormally low or high according to their function.

In the current study fibrinolysis was measured indirectly only from the level of PAI-1, an inhibitor of fibrinolysis, due to the limited availability of the commercial kit. The circadian variation of PAI-1 demonstrated the peak level in the morning and the lowest level at night. Our patients had the first blood sample drawn during asthma exacerbations: 13 children (59\%) had asthma exacerbation in the morning, and 9 children had asthma exacerbation in the evening, which should be the lowest level of PAI- 1 according to the circadian variations. In addition, the second blood samples during the stable asthma stage were collected in the morning, which was demonstrated to be the peak level. However, our study demonstrated that the level of PAI-1 during asthma exacerbation increased significantly compared with the level of PAI-1 at the stable stage, even though the blood samples were drawn in the morning during the peak level of PAI-1. Further study on the role of fibrinolysis and asthma exacerbation should be evaluated by measuring plasmin, plasminogen, or plasmin- $\alpha_{2}$-antiplasmin complex.

\section{Conclusion}

This study demonstrated evidence of increased endothelial activation and increased PAI-1 during asthma exacerbation. D-dimer, the smallest subunit of fibrin degradation products from clot formation and fibrinolysis, was positively correlated with the severity of asthma exacerbation. Protein C, an important anticoagulant protein that enhances fibrinolysis, was significantly lower during early asthma exacerbation. Anticoagulants or activated protein $\mathrm{C}$ may have a role in treating severe asthma exacerbation.

\section{Acknowledgments}

We are grateful to Assoc. Prof. Punnee Butthep, Mr. Arjitr Trirakanchanaand, and Mr. Anucha Soisamrong for assisting with protein $\mathrm{C}$ activity and D-dimer measurements. We would like to thank Ms. Cherapat Sasisakulporn and Ms. Wanlapa Jotikashira for their help in blood sampling. This study was supported by a research grant from the Faculty of Medicine, Ramathibodi Hospital, Mahidol University, Bangkok, Thailand.

\section{References}

1 Manuyakorn W, Howarth PH, Holgate ST: Airway remodelling in asthma and novel therapy. Asian Pac J Allergy Immunol 2013;31:310.

2 Schouten M, Van De Pol MA, Levi M, Van Der Poll T, Van Der Zee JS: Early activation of coagulation after allergen challenge in patients with allergic asthma. J Thromb Haemost 2009; 7:1592-1594.

3 Kemona-Chetnik I, Kowal K, Kucharewicz I, Pampuch A, Bodzenta-Lukaszyk A: Thrombin activatable fibrinolysis inhibitor (TAFI) in allergic asthma patients (in Polish). Przegl Lek 2006;63:1281-1285.

4 Kemona-Chetnik I, Bodzenta-Lukaszyk A, Kucharewicz I, Rogalewska AM: Tissue factor and tissue factor pathway inhibitor during specific bronchial challenge in allergic asthma patients (in Polish). Przegl Lek 2005;62:98-101.

5 Takemura M, Matsumoto H, Niimi A, Ueda T, Matsuoka H, Yamaguchi M, Jinnai M, Muro S, Hirai T, Ito Y, Nakamura T, Mio T, Chin K, Mishima M: High-sensitivity C-reactive protein in asthma. Eur Respir J 2006;27:908-912.

6 Fujita M, Ueki S, Ito W, Chiba T, Takeda M, Saito N, Kayaba H, Chihara J: C-reactive protein levels in the serum of asthmatic patients. Ann Allergy Asthma Immunol 2007;99:48-53.

7 Razi E, Ehteram H, Akbari H, Chavoshi V, Razi A: Evaluation of high-sensitivity C-reactive protein in acute asthma. Tanaffos 2012;11:3237.
8 Zietkowski Z, Skiepko R, Tomasiak-Lozowska MM, Mroczko B, Szmitkowski M, BodzentaLukaszyk A: Changes in high-sensitivity C-reactive protein in serum and exhaled breath condensate after intensive exercise in patients with allergic asthma. Int Arch Allergy Immunol 2010;153:75-85.

9 Levi M, van der Poll T: Inflammation and coagulation. Crit Care Med 2010;38:S26-S34.

10 Chuansumrit A, Chaiyaratana W: Hemostatic derangement in dengue hemorrhagic fever. Thromb Res 2014;133:10-16.

11 van Wissen M, Keller TT, van Gorp EC, Gerdes VE, Meijers JC, van Doornum GJ, Büller HR, Brandjes DP: Acute respiratory tract infection leads to procoagulant changes in human subjects. J Thromb Haemost 2011;9:1432-1434.

12 Preutthipan A: Status asthmaticus; in Khositseth A, Limrungsikul A (eds): Pediatrics Critical Care. Bangkok, Deewan, 2013, pp 495-510.

13 The Global Strategy for Asthma Management and Prevention, Global Initiative for Asthma (GINA) 2014. http://www.ginasthma.org/.

14 Pintadit P, Chuansumrit A, Chotsupakarn S, Krasaesub S, Panthankul W, Isarangkura P: Carrier detection in hemophilia A by using the ratio of factor VIII clotting activity and von Willebrand factor antigen. Thai J Hematol Transf Med 1996;6:24-31.

15 Levi M, Schultz MJ, Rijneveld AW, van der Poll $\mathrm{T}$ : Bronchoalveolar coagulation and fibrinolysis in endotoxemia and pneumonia. Crit Care Med 2003;31:S238-S242.
16 Aird WC: Phenotypic heterogeneity of the endothelium. I. Structure, function, and mechanisms. Circ Res 2007;100:158-173.

17 Page AV, Liles WC: Biomarkers of endothelial activation/dysfunction in infectious diseases. Virulence 2013;4:507-516.

18 Neyrinck AP, Liu KD, Howard JP, Matthay MA: Protective mechanisms of activated protein $\mathrm{C}$ in severe inflammatory disorders. Br J Pharmacol 2009;158:1034-1047.

19 Majoor CJ, van de Pol MA, Kamphuisen PW, Meijers JC, Molenkamp R, Wolthers KC, van der Poll T, Nieuwland R, Johnston SL, Sterk PJ, Bel EH, Lutter R, van der Sluijs KF: Evaluation of coagulation activation after rhinovirus infection in patients with asthma and healthy control subjects: an observational study. Respir Res 2014;15:14.

20 Boyle JP, Smart RH, Shirey JK: Heparin in the treatment of chronic obstructive bronchopulmonary disease. Am J Cardiol 1964;14:25-28.

21 Fine NL, Shim C, Williams MH Jr: Objective evaluation of heparin in the treatment of asthma. Am Rev Respir Dis 1968;98:886-887.

22 Hataji O, Taguchi O, Gabazza EC, Yuda H, Fujimoto $\mathrm{H}$, Suzuki K, Adachi Y: Activation of protein C pathway in the airways. Lung 2002; 180:47-59.

23 Danese S, Vetrano S, Zhang L, Poplis VA, Castellino FJ: The protein $\mathrm{C}$ pathway in tissue inflammation and injury: pathogenic role and therapeutic implications. Blood 2010;115: $1121-1130$. 